\title{
Effect of saturation and post processing on 3D printed calcium phosphate scaffolds
}

Tamas D. Szucs, Dermot Brabazon

School of Mechanical and Manufacturing Engineering, Dublin City University, Dublin, Ireland

\begin{abstract}
.
Three dimensional printing was investigated for fabricating hydroxyapatite (HA) and $\beta$ tricalcium phosphate $(\beta$-TCP) composite scaffolds using calcium phosphate based ceramics and calcium phosphate cement chemistry. Scaffolds were formed by printing an aqueous sodium phosphate solution on the powder bed consisting of a mixture of dicalcium phosphate anhydrous (DCPA) and calcium hydroxide powders. The sodium phosphate solution was functioning as a binder material and also as the initiator of the wet chemical reaction. Compressive mechanical properties of printed samples were examined as a function of saturation level that was inversely proportional to the powder to liquid ratio. To increase mechanical properties and obtain hydroxyapatite and $\beta$-TCP composites, the printed samples were sintered. The effect of sintering parameters including dwell time and sintering temperature were also examined. X-ray diffraction (XRD) was used to examine material composition at different stages of the manufacturing process and to confirm the presence of HA and $\beta$-TCP in the final stage. The effect of sintering procedure on the surface topology of the samples was examined using scanning electron microscopy (SEM).
\end{abstract}

\section{Introduction}

Three dimensional printing (3DP) is an attractive rapid prototyping technology in tissue engineering as it has the ability to fabricate customized 3-dimensional $\mathrm{CaP}$ scaffolds with predesigned external and internal geometry using calcium phosphate ceramic (CPC) chemistry [13]. 3DP is a powder based additive manufacturing technology where the powder particles are selectively bonded in a thin layer of powder material by adhesive droplets. The thin 2D layers are bonded on top of each other to form the 3D solid structure. The built object in both cases is supported by the unprocessed powder therefore it is possible to fabricate overhanging features allowing for porous structures with designed internal architecture. A key advantage of 3DP is that a large variety of materials can be used given that they are available in the form of powder [4] Calcium phosphate ceramics were chosen due to their biocompatibility, bioactivity, successful clinical history and similarity to the mineral phase of natural bone. The use of calcium phosphate ceramics for 3DP was previously demonstrated by several authors [2, 3, 5-7]. The present study investigates the effect of cement powder to mixing liquid (P/L) ratio since it is the main determining factor of porosity and therefore of mechanical properties. Mechanical 
properties increase exponentially with decreasing porosity[8]. Furthermore, sintering as a post processing technology was examined for increasing mechanical properties of printed scaffolds.

\section{Materials and Methods:}

A homogeneous mixture of medical grade dicalcium phosphate anhydrus (DCPA, CaHPO4, 12038 Sigma-Aldrich) and calcium hydroxide $\left(\mathrm{Ca}(\mathrm{OH})_{2}\right.$, Lianyungang Debang Fine Chemical Co., Lianyungang, China) was dried and then quantified stoichiometrically in a 5/3 molar ratio of $\mathrm{Ca} / \mathrm{P}$. The powders were mixed in a V-blender for $30 \mathrm{~min}$ at $40 \mathrm{rpm}$ and then were loaded into a Z310 3 dimensional printer (Z-Corp, Burlington, MA). Sodium phosphate solution $\left(\mathrm{Na}_{2} \mathrm{HPO}_{4}\right.$, S7907

Sigma-Aldrich, Schnelldorf, Germany) was introduced to the mixture through the print-head as the binder material and the initiator of the precipitation reaction.

The effect of $\mathrm{P} / \mathrm{L}$ ratio and post processing on the porosity and mechanical properties of the scaffolds were examined. The effect of varying saturation levels of printing (i.e. the inverse of $\mathrm{P} / \mathrm{L}$ ratio) were evaluated at two levels of 0.25 and 0.45 . Printed specimens were subjected to sintering at different temperatures of $800,1000,1200{ }^{\circ} \mathrm{C}$ for different dwell times of 1,3 , and 5 hours. The heating rate for all specimens was $5^{\circ} \mathrm{C} / \mathrm{min}$.

Phases prior and phase transformations after sintering were analyzed using XRD operated at 40 $\mathrm{kV}$ and $40 \mathrm{~mA}$ at a 20 range of $15-60^{\circ}$ employing a step size of 0.02 and a 5 s exposure. Porosity of raw specimens was tested according to ISO 623-2 using Micrometrics AccuPyc 1330 helium pycnometer. Compressive modulus and yield strength were evaluated at $1 \mathrm{~mm} / \mathrm{min}$ test speed using Zwick/Roell Z050 universal testing machine equipped with a $5 \mathrm{kN}$ load cell. Surface topology was qualitatively evaluated using Scanning Electron Microscopy (SEM, Zeiss EVO LS $15)$.

\section{Results and Discussions:}

XRD data showed that precipitated hydroxyapatite (PHA) was produced gradually by 3D printing sodium phosphate solution to the mixture of DCPA and $\mathrm{Ca}(\mathrm{OH})_{2}$ powder. Aside from PHA, remaining DCPA and $\mathrm{Ca}(\mathrm{OH})_{2}$ phases were present in the printed samples. The presence of starting chemicals in the printed samples is an indicator of incomplete chemical reaction and limited contact between binder and powder during the printing. It was also observed that the sintered PHA specimens were able to decompose into 13-Tricalcium Phosphate (13-TCP) and Hydroxyapatite (HA). Fig. 1. shows the XRD data for the two staring powders (DCPA and $\left.\mathrm{Ca}(\mathrm{OH})_{2}\right)$, for a specimen printed at 0.4 saturation level (PHA), and for samples post-processed by sintering at $1100{ }^{\circ} \mathrm{C}$ for 1 hour ( $\beta$-TCP and HA). 


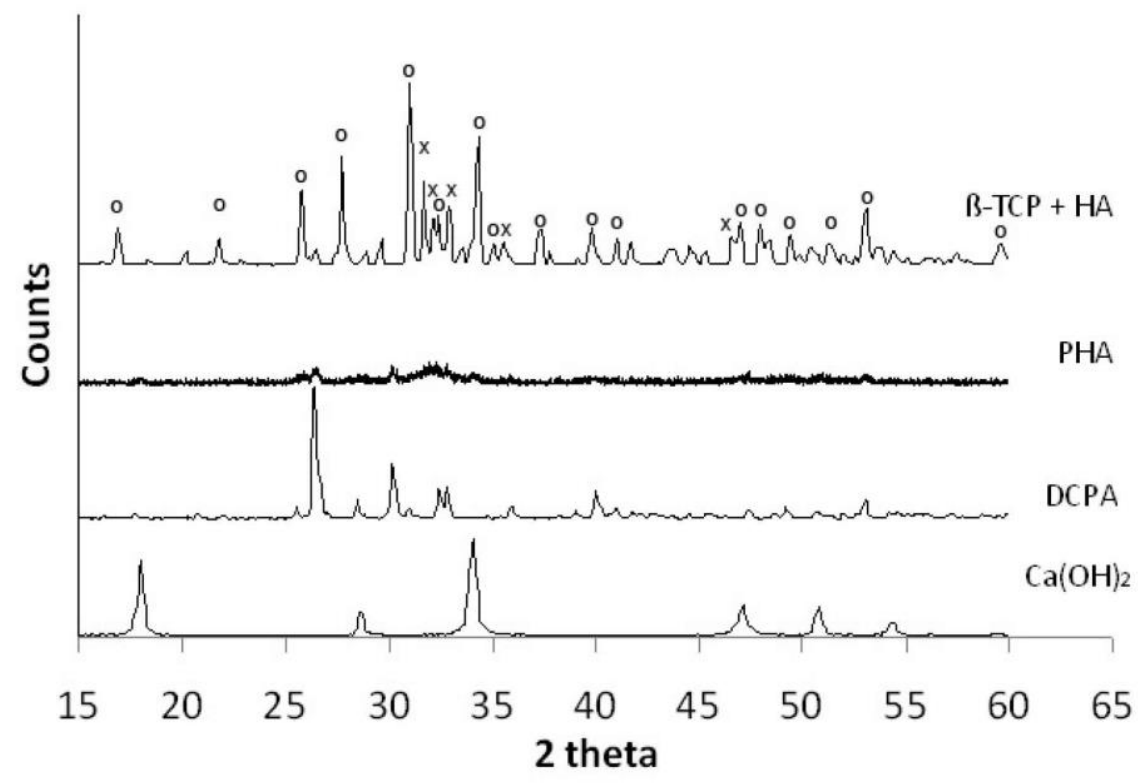

Fig. 1. 3DP resulted in the formation of Precipitated Hydroxyapatite (PHA) by wet-chemical synthesis as described by Eq.1.

$$
\mathrm{CaHPO}_{4}+\mathrm{Ca}(\mathrm{OH})_{2}+\mathrm{HPO}_{4}^{2-} \longrightarrow \mathrm{Ca}_{10-\mathrm{x}}\left(\mathrm{HPO}_{4}\right)_{\mathrm{x}}\left(\mathrm{PO}_{4}\right)_{6-\mathrm{x}}(\mathrm{OH})_{2-\mathrm{x}}
$$

Additionally to the observed PHA, remaining DCPA and $\mathrm{Ca}(\mathrm{OH})_{2}$ phases were also present in the printed samples. This was possibly due to limited contact between binder and powder during $3 \mathrm{D}$ printing and is an indicator of incomplete chemical reaction. Depending on the $\mathrm{Ca} / \mathrm{P}$ ratio of the starting materials, when heated to above $700{ }^{\circ} \mathrm{C}$, PHA is capable to decompose into 13-TCP and HA (1.67 > Ca:P > 1.50) [8]. In the sintered samples both $\beta$-TCP and HA phases were detected. The reaction taking place during sintering is described by Eq. 2

$$
\mathrm{Ca}_{10-\mathrm{x}}\left(\mathrm{HPO}_{4}\right)_{\mathrm{x}}\left(\mathrm{PO}_{4}\right)_{6-\mathrm{x}}(\mathrm{OH})_{2-\mathrm{x}} \longrightarrow \beta-\mathrm{Ca}_{3}\left(\mathrm{PO}_{4}\right)_{2} \mathrm{Ca}_{10}\left(\mathrm{PO}_{4}\right)_{6}(\mathrm{OH})_{2}
$$

Saturation was found to be the most significant parameter influencing compressive properties. Compressive strength of printed, unsintered samples increased from 0.06 to $0.21 \mathrm{MPa}$ while their stiffness increased from 1.8 to $9.5 \mathrm{MPa}$ by increasing saturation level from 0.25 to 0.45 . Porosity values of $79 \%$ and $76.8 \%$ were recorded for saturation levels of 0.25 and 0.45 respectively. Results showed that when the saturation level was low mechanical properties deteriorated. This was not consistent with previous findings of Bohner et al. [8]. It is believed that the poorer mechanical properties at the lower saturation level was due to incomplete wet chemical synthesis resulting from limited contact between the powder and the liquid phase. This assumption was supported by XRD results as remaining DCPA and $\mathrm{Ca}(\mathrm{OH})_{2}$ phases were detected in printed specimens. 
The same tendency was observed for compressive modulus on specimens sintered at various temperatures as it increased from 0.09 to $0.356 \mathrm{MPa}$ with increase from saturation level of 0.25 to 0.45

Sintering significantly improved compressive behaviour of the samples printed at low saturation levels. The modulus, E, increased from 1.8 MPa up to a maximum of 4.3 MPa and compressive yield strength, acy, increased from 0.06 MPa up to a maximum of 0.156 MPa. Smaller increases in modulus and strength were noted for the higher saturation level after sintering. The modulus increased from 9.5 MPa up to a maximum of $11.1 \mathrm{MPa}$ and compressive yield strength increased from 0.21 MPa up to a maximum of 0.35 MPa. Sintering time had no significant effect within the examined range indicating that decomposition time to HA and p-TCP is less than 60 minutes. Increased sintering temperatures resulted in improved mechanical properties possibly suggesting that to complete decomposition of HA temperatures higher than $800^{\circ} \mathrm{C}$ are required.

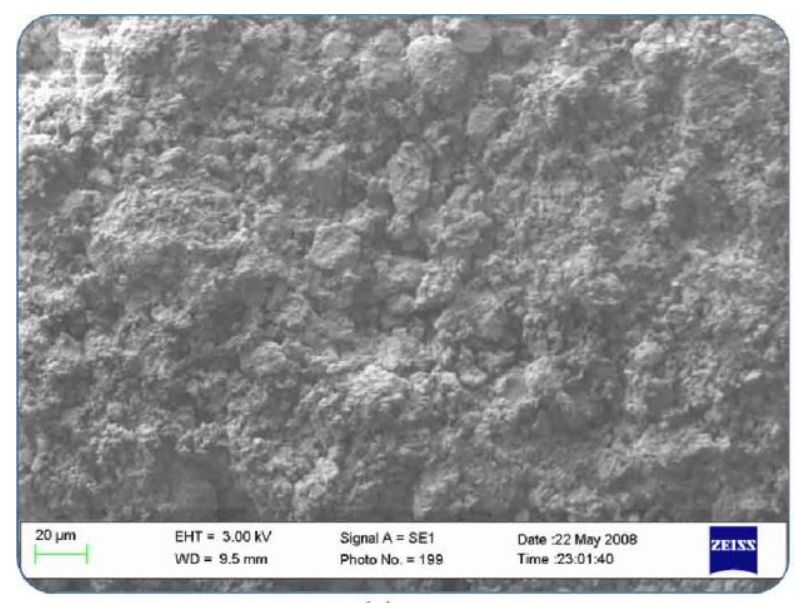

(a)

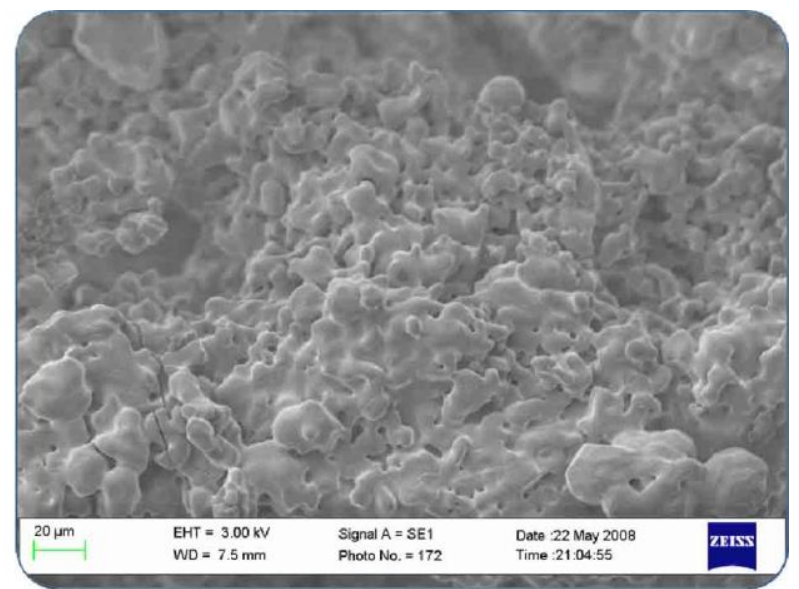

(b)

Fig. 2. SEM images before (a) and after (b) sintering

It can be seen in the SEM images that on the surface of un-sintered specimens surface separate particles can be observed and particles are loosely bound together. On the sintered samples neck formation and particle coalescence are prevalent. The significant drop in the specific surface area after sintering is clearly visible on the images, however from tissue engineering point of view it is more advantageous to have rough surfaces with high surface to volume ratio than smooth surfaces. Rougher surfaces facilitate cell attachment [4].

\section{Conclusions}

PHA scaffold were fabricated by wet chemical synthesis using 3DP technology. Increase in saturation level of printing substantially improved mechanical properties of the samples. 
Compressive and modulus behaviour was further improved by sintering. This was more notable at the lower level of saturation. Compressive strength and stiffness also increased at higher sintering temperatures. Furthermore, sintering decreased specific surface area and increased porosity of the specimens. It must be noted that obtain mechanical properties are still not sufficient for load bearing applications. Further post processing such as infiltration with biodegradable polymers should be considered.

\section{Acknowledgements}

The authors would like to thank to Ms. Szilvia Eosoly, Mr. Yurong Liu and Dr. Aran Rafferty for their support. This research has been supported by a Marie Curie Early Stage Research Training Fellowship of the European Community's Sixth Framework Programme under contract number MEST-CT-2005-020621.

\section{References}

1. U. Gbureck, E. Vomdran, F. A. Muller, J. E. Barralet Journal of Controlled Release Vol. 122 (2007), p. 173.

2. A. Khalyfa, S. Vogt, J. Weisser, G. Grimm, A. Rechtenbach, W. Meyer, M. Schnabelrauch Journal of Materials Science: Materials in Medicine Vol. 18 (2007), p. 909.

3. U. Gbureck, T. Holzel, U. Klammert, K. WUrzler, F. A. Milner, J. E. Barralet Advanced Functional Materials Vol. 17 (2007), p. 3940.

4. W.-Y. Yeong, C.-K. Chua, K.-F. Leong, M. Chandrasekaran Trends in Biotechnology Vol. 22 (2004), p. 643.

5. H. Seitz, W. Rieder, S. Irsen, B. Leukers, C. Tille J Biomed Mater Res B Appl Biomater Vol. 74 (2005), p. 782.

6. R. Chumnanklang, T. Panyathanmapom, K. Sitthiseripratip, J. Suwanprateeb Materials Science and Engineering: C Vol. 27 (2007), p. 914.

7. B. Leukers, H. GUlkan, S. Irsen, S. Milz, C. Tille, M. Schieker, H. Seitz Journal of Materials Science: Materials in Medicine Vol. 16 (2005), p. 1121.

8. M. Bohner Injury Vol. 31 (2000), p. 37. 